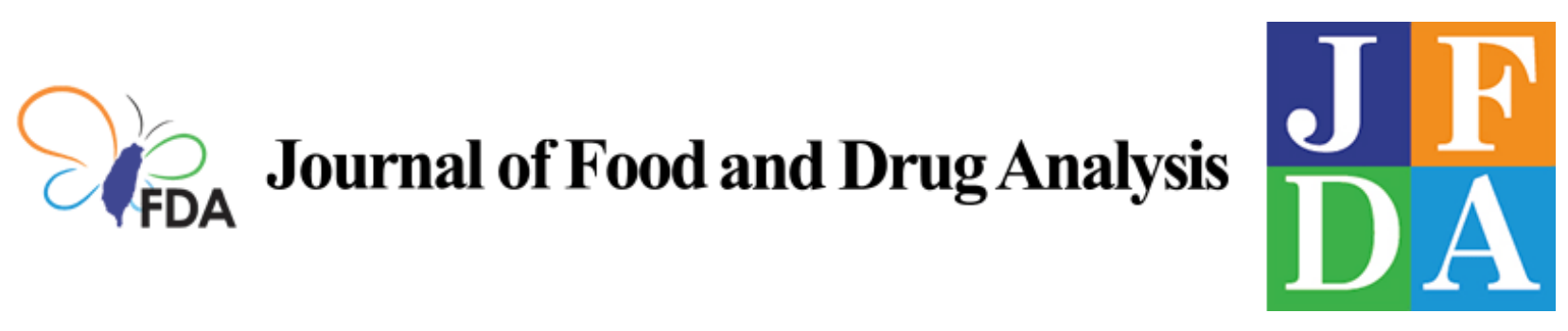

\title{
Corrigendum to "Shenmai-Yin decreased the clearance of nifedipine in rats: The involvement of time-dependent inhibition of nifedipine oxidation"
}

Follow this and additional works at: https://www.jfda-online.com/journal

Part of the Food Science Commons, Medicinal Chemistry and Pharmaceutics Commons, Pharmacology Commons, and the Toxicology Commons

(c) (i) (9)

This work is licensed under a Creative Commons Attribution-Noncommercial-No Derivative Works 4.0 License.

\section{Recommended Citation}

Ueng, Yune- Fang (2020) "Corrigendum to "Shenmai-Yin decreased the clearance of nifedipine in rats: The involvement of time-dependent inhibition of nifedipine oxidation"," Journal of Food and Drug Analysis: Vol. 28 : Iss. 3 , Article 11.

Available at: https://doi.org/10.38212/2224-6614.3169

This Corrigendum is brought to you for free and open access by Journal of Food and Drug Analysis. It has been accepted for inclusion in Journal of Food and Drug Analysis by an authorized editor of Journal of Food and Drug Analysis. 


\section{Corrigendum}

Available online 28 August 2020.

$\mathrm{T}$ his is an announcement to correct the full name of the affiliation which author YuneFang Ueng belongs. The full name of the affiliation of "Institute of Medical Sciences (Taipei Medical University)" should be "Graduate Institute of Medical Sciences, College of Medicine, Taipei Medical University".

Articles:

1. Corrigendum to "Shenmai-Yin decreased the clearance of nifedipine in rats: The involvement of time-dependent inhibition of nifedipine oxidation" [J Food Drug Anal 27 (2019) 284-294].

Full Text:

Shenmai-Yin decreased the clearance of nifedipine in rats: The involvement of time-dependent inhibition of nifedipine oxidation

Hong-Jaan Wang a, Chung-Kuang Lu b,e, Wei-

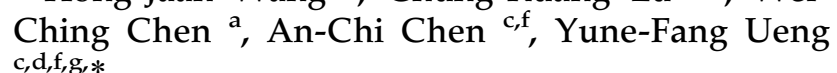

a School of Pharmacy, National Defense Medical Center, Taipei, Taiwan
${ }^{b}$ Division of Chinese Medicinal Chemistry, National Research Institute of Chinese Medicine, Taipei, Taiwan

c Division of Basic Chinese Medicine, National Research Institute of Chinese Medicine, Taipei, Taiwan

d Graduate Institute of Medical Sciences, College of Medicine, Taipei Medical University, Taipei, Taiwan

e Department of Life Sciences and Institute of Genome Sciences, School of Life Sciences, National Yang-Ming University, Taipei, Taiwan

f Institute of Biopharmaceutical Sciences, School of Pharmacy, National Yang-Ming University, Taipei, Taiwan

g Institute of Pharmacology, School of Medicine, National Yang-Ming University, Taipei, Taiwan 